\title{
Linking Long-Term Trends of Female Unpaid Work and Macro Economy: A Preliminary Modeling of Pakistan Data
}

\author{
Sajjad Akhtar \\ Member (Economic Statistics) \\ Pakistan Bureau of Statistics \\ Pakistan
}

\begin{abstract}
During 1991-2015, the female contributing family workers (CFWs) in agriculture in Pakistan fluctuated between 52-71 percentages. In spite of Pakistan's transition to a lower middle income country in the last 25 years, the phenomena of secular decline in the share of female CFWs in agriculture remains weak. This paper is an initial attempt to explore, model and quantify the links of macro economy to long-term trends of female CFWs in agriculture in the country. Three separate reduced form specifications are estimated to explain the participation of CFWs in agriculture: i) Intra-farm allocation of CFWs labor supply, ii) Wage-Price impacts and iii) Farm based activity. The results identify and quantify the contribution of macro drivers such as unemployment rates, education, sectoral job opportunities, wages and farm practices and activities in explaining the long-term trends' for female CFWs in Pakistan.
\end{abstract}

Keywords: contributing family workers, females, agriculture, long-term trends, macro determinants, reduced form modeling, intra-farm allocation, wage-price impacts, farm-based activity.

\section{Introduction}

Historically, Pakistan's female labor force participation rate (LFPR) has remained low and lowest among the two other South Asian countries, namely India and Bangladesh. ${ }^{1}$ Nationally, in 2014-15 it was 22.0 percent. However in rural areas it has always been higher than in urban areas. In 2014-15, it was roughly 3 times higher in rural than in urban areas. During 1991-2015 female LFPR in rural areas increased from 14.8 to 28.8 percent. In contrast, in India, female LFPR in rural areas fell from roughly 55percent in 1987 to 44 percent in 2011-12. Rehman \& Islam (2013)found in Bangladesh that the female LFPR in rural areas also increased from 17.4 percent in 1995-96 to 36.4 percent in 2010 . $^{2}$ This low but rising female participation rate in rural areas of Pakistan obscures number of issues related to the efficient and effective functioning of labor market, including those related to 'quantity' vs 'quality' of jobs for women in rural areas and specifically in the agriculture sector. A large segment of women in labor force in rural areas are engaged as 'contributing family workers (CFWs)' as per more recent nomenclature adopted in the labor force surveys of Pakistan switching from an earlier one of 'unpaid family helpers' ${ }^{3}$ In case of Pakistan, the share of female CFWs in agriculture as a percentage of female labor force in rural areas fluctuated between 52-71 percent during the period 1991-2015. At a macro level it raises the question that whether this trend in employment status of female CFWs in Pakistan is consistent with the growth patterns and changing structure of the national economy. This requires relating longer time trends of CFWs in agriculture to sectoral structure, growth and investment patterns of the economy along with the evolution of socio demographic profile of female CFWs. At a micro level the questions relate to vulnerability, 'hidden underemployment' in terms of hours of work, measuring the productivity and contribution to income and/or consumption of CFWs within macro economy and socio-demographic household determinants of entry into this specific employment status. Research on female unpaid work follows two strands: First strand consists of research on unpaid work within the production boundary of the System of National Accounts (SNA) and concentrates on estimation techniques to quantify the contribution of the female unpaid work in national accounts.

\footnotetext{
${ }^{1}$ LFPR=refined activity rate is the currently active population expressed as percentage of the population 10 years and above.

${ }^{2}$ Pakistan: Various Issues of LFS. http://www.ideasforindia.in/article.aspx?article_id=1782.

${ }^{3}$ Contributing family worker is a person who works without pay in cash or in kind on an enterprise operated by a member of his/her household or other related persons. 
The research by Fontana (2013) relies on time-use, labor force and household income expenditure surveys for simple valuation or economy-wide impacts of female unpaid work through the use of Computable General Equilibrium (CGE) Models. The second strand recognizes female unpaid work that falls outside the production boundary (non-SNA). Various authors have provided convincing conceptual justifications for unpaid work (NonSNA) linkages to macro economy and the need for its valuation through constructing satellite accounts. However Hirway (2015) observes, "the task of valuation can be considered a 'work in progress......the task of integrating unpaid work (Non-SNA) with the mainstream economy by compiling satellite accounts is still a pending task'.

In case of Pakistan, although considerable empirical research exists on modeling the determinants of female labor force participation rate (see Isran \& Isran (2012), Ejaz (2011), Sarwar \& Abbasi (2013)), research on female unpaid work is still in its infancy. Constrained by a single time use survey conducted in 2005-06, most of the work consists of profiling female CFWs from labor force surveys. However, Arshad (2008) acknowledged and quantified the contribution of female CFWs in national accounts. In Shahnaz, et al., (2008), an attempt was made to model the socio-economic household determinants of participation probabilities of CFWs and their impact on the national unemployment rate and household consumption comparing LFS of 2001-02 and 2005-06. This paper revisits the participation rate of CFWs, but is particularly more focused on female CFWs in agriculture in Pakistan, i.e., female unpaid work within the production boundary (SNA), as they constitute by far the majority of female CFWs in the country. Moreover the area of interest in this paper is the search for macro determinants of fluctuating longer 25 year time trends of CFWs during 1990-91 to 2014-15. Given the challenge and evolving state of 'gender-aware' macro modeling, this paper is an exploratory attempt at reduced-form modeling of longterm linkages between the macro economy and female CFWs (SNA variety) in Pakistan. The structure of the paper is as follows:- The next section briefly presents a visual analysis of the last 25 year trends of female labor market indicators of interest and used in subsequent analysis. Section 3 outlines conceptual and operational links of CFWs to macro economy. Results of reduced form modeling of linkages between female CFWs and macro economy are discussed in section 4 . The last section is left for summary and policy implications.

\section{Visual analysis of few female labor market indicators in rural areas}

Figs. 1-3 give the long-term trends of few indicators of female labor market indicators in rural Pakistan. ${ }^{4}$ After a brief fluctuation, and stagnancy in the nineties, the female LFPR in rural areas rose consistently. ${ }^{5}$ Conversely, the open unemployment rate of females in rural areas fluctuated between 8.5 percent (1993-94) and 14.6 percent (1996-97) in the nineties and early part of $21^{\text {st }}$ century and then fell rapidly in matter of 3 years from 11 to 8 percent, falling and fluctuating within the narrow range of 6-8percent during 2005-06 to 2014-15. ${ }^{6}$ In contrast, in Fig 2, percentage of females in unpaid work in agriculture fluctuated in the range of 52-66 percent during the nineties. It began to rise continuously from 2000-01 to a high of 71 percent in 2008-09, followed by a steady decline to 58 percent in 2014-15. ${ }^{7}$ As per Shahnaz, et al., (2008) during 2001-02 and 2005-06, 60 percent of growth in national employment was accounted by the growth in CFWs(both sexes at national level).Correspondingly, the percentage of males in unpaid work in agriculture, although $1 / 3^{\text {rd }}$ of female workers, fluctuated in the narrow band of 15-19 percent during the nineties. In matter of 2 years it rose suddenly from 16.8 percent in 2001-02 to 19.4 percent in 2003-04. Till 2009-10 it fluctuated between 19-21 percent, and then declined to 15.5 percent in 2014-15. Note that the long term trends in unpaid work of both sexes are roughly parallel. In Fig.3, trend of a ratio of the percentages shown in Fig.2 is calculated and graphed. Given an intra-farm and intra-household dynamics of decision making, one can expect the trend of the ratio to be influenced by three different forces; a) the ratio can remain unchanged if the growth rate of shares is the same for both sexes, b) the ratio will rise/fall if the growth rate of share of female CFWs is higher/lower than the corresponding growth rate of male CFWs, c) if in percentage points terms, the increase/decrease is same or different for both denominator and numerator, the absolute value of ratio will decrease/increase although the shape of the trend will be the same.

\footnotetext{
${ }^{4}$ In a period of 25 years, i.e., during 1990-91 and 2014-15, the analysis is based on yearly data points extracted from 19 LFS held during the period. LFS was not undertaken in 1995-96, 98-99, 2000-01, 02-03, 04-05 and 2011-12.

${ }^{5}$ Defined as: Total female civilian labor force 10 year $\&$ above in rural areas $\div$ Total female population 10 year and above in rural areas.

${ }^{6}$ Defined as: Total number of female unemployed 10 year $\&$ above in rural areas $\div$ Total female civilian labor force 10 year and above in rural areas.

${ }^{7}$ Female CFWs are defined in percentage terms as number of female involved in unpaid work in agriculture divided by total of female labor force in rural areas.
} 
In the presence of above forces the ratios' observed yearly movement is different from the trend of the original indicators given in Fig. 2. The ratio is stagnant till 1993, rises and peaks in 1997, falls in 1998, and once again is stable for the next 10 years between 3.0-3.5 and begins to rise afterwards. ${ }^{8}$

\section{Conceptual and operational sketch of macro links.}

The formalization of long-term macro determinants of participation rate of unpaid work (SNA) requires a multidirectional framework. In a neoclassical framework the decision to supply how much labor, at what price, at what time, where and to whom, depends on the individual. Some have argued (Abraham, 2008), "that individual decision making at subsistence income levels does not attempt to optimize the individual utility. Rather, members in households at subsistence income try to acquire the basic subsistence income for all members in the family. Thus the labor supply of a household is a joint utility function of the household". Specifying a joint utility function for female unpaid workers is complex and acknowledges egoistic, altruistic, and caring type of agents within a household. The arguments in the joint utility function can be additive or multiplicative. Treating female unpaid work (SNA type) coming from secondary workers, whose labor supply is a buffer and/or complementary/supplementary as well time variant, is a constrained(over the time space as well attribute space) maximization of joint utility function. Thus, female involvement in unpaid work (SNA type) specifically in agriculture is relative to the labor supply of a primary bread winner, male labor supply in unpaid work, fixed and time varying own attributes, and price and wage signals that she and her primary worker or competing male CFWs receives from the market over time. At a macro level in an operational sense the determinants of CFW labor supply and demand can be represented by host of indicators including) female LFPR relative to male in rural areas, ii) female unemployment relative to male unemployment in rural areas, iii) gender differentials in earnings/wages, iv) farm and off-farm production envelope, v) personal attributes, i.e., education level, age (as a proxy for involvement in caring work) and vi) price-wage nexus and signals of sectoral growth from the market.

The search for reduced form specification and estimation of impact of macro drivers oflong-term trend in the participation of females CFWs in agriculture in this paper is circumscribed by limited number of observations (19) against the availability of a relatively large number of drivers (24), leaving zero degrees of freedom. Consequently, in an exploratory analysis, the multidimensional framework is broken down into three reduced form specifications. All the three specifications are weakly hybrid but can be broken into three thematic areas based on the common characteristics of the majority of the arguments in each specification. The theme of the first specification concentrates on modeling the trends in the CFW female/male ratio (shown in Fig.3) as a result of Intra-farm allocation of CFW's labor supply influenced by labor market indicators of rural areas, sectoral job opportunities and female education and age. The second specification mainly captures the influence of macro wage-price trends on the demand for female CFWs. The third specification is a female farm based activity model focused on traditional roles of females.

\section{Results}

\subsection{Model 1:Intra-farm Allocation of CFW' labor Supply}

Table 1 gives the estimated results of 5 variants of Intra-farm allocation model. We note the following:

a) A priori, whether the ratio of percentage of female to male CFW's (UNPDRATIO) is inversely or directly related to ratio of male to female labor force participation rate (LFPRATIO) remains an empirical question. If female participation in unpaid work on farm is reduced when LFPRATIO goes up, one can interpret it as an income effect accruing from higher participation of male(including male CFWs), in the labor force of rural areas. Alternatively, if UNPDRATIO goes up along with LFPRATIO then it is the substitution effect at work. The results from Pakistan support the income effect in 2 out of 5 versions of the model and current value of LFPRATIO is statistically more robust than its lag response. In other three variants, the impact of LFPRATIO $(-1)$ is positive, but statistically not significant.

b) Two variants of unemployment ratio are tested: i) UNEMPLRATIO, ratio of urban to rural unemployment rate and ii) UNEMPLRURRATIO, ratio of female to male unemployment rates in rural areas.

\footnotetext{
${ }^{8}$ The correlation between the ratio and share of female CFWs and male CFWs is 0.20 and -0.64 respectively and statistically significant at 99 percent level for male CFWs. The correlation between the two shares is 0.62 and statistically significant at 99 percent level. 
The long-term trends in female unpaid work in agriculture are more sensitive to the ratio of unemployment rates of female to males in rural areas rather than to rural/urban unemployment rates. As expected as the former ratio goes up the use of female as a 'buffer' or secondary worker in agriculture also goes up (variant 3,4 and 5). Note also the robustness of the magnitude $(0.234-0.298)$ of the impact across the 3 variants However, the statistical significance and negative impact of locational unemployment rate (UNEMPLRATIO) in variant 1 suggests that it lowers female unpaid work as the 'substitution effect' may operate through return migration of males (previously CFWs) from urban areas.

c) Over the last 15 out of the 25 years, job opportunities for midwives and lady health visitors (LHVs) in rural areas expanded considerably. Between 1990-91, and 2014-15, the average annual growth rate of midwives and LHVs was 3.4 and 6.9percent respectively. Consequently except in two years, the ratio of midwives to LHVs (JOBRATIO) declined from 4.83 to 2.20 during the period. The positive impact of JOBRATIO and JOBRATIO(-1) in all the 5 variants of the model suggest that as this ratio decreased due to faster expansion of LHVs relative to midwives, the ratio of CFWs female share to male share also fell. Out of 5 estimates, three estimates are in the range of 0.716 and 0.783 . Increase in regular off-farm job opportunities for educated females (midwives and LHVs) lead to a decline in the share of female CFWs in agriculture and vice a versa. ${ }^{9}$

d) Education level of females is represented by three variables: YREDFRR is the average years of education of female labor force in rural areas constructed from the Labor Force Surveys. ENRLMDL and ENRLHIGH are two macro level indicators and represent yearly trend of total female enrolment in middle and secondary schools respectively at the national level.YREDFRR is used in two variants of the model, namely in variant 1 and 3.Its impact is positive, is not robust and statistically significant in only variant $1 .{ }^{10}$ In equations 2,4 and 5, the impact of ENRLMDL and ENRLHIGH is estimated on the ratio of CFWs female share to male share. Though the impact of increasing enrolment in middle schools over the period is a reduction in the ratio of female to male unpaid workers, it is statistically significant only in variant 2 . Increasing enrolment of females in middle schools leading to reduction in unpaid work may be due to substitution of females from SNA variety to Non-SNA variety. ${ }^{11}$ In case of increasing enrolment of females in high schools (variant 2 and 4 ), it leads to higher CFW ratio. This is likely a substitution effect where sending girls to high schools necessitates higher involvement of existing older family females or other un-enrolled female relatives in unpaid work. ${ }^{12}$

e) In a longer term framework, sectoral growth in the economy can impact the trends in the supply of female unpaid work, either as 'buffer' supply (substitution effect) or through self and primary worker income earning opportunities existing outside agriculture (income effect). This is tested by including 3 macro level indicators of sectoral growth: i) GRGGS (Annual growth rate of General Govt. Services), ${ }^{13}$ ii) GRSSM (Annual growth rate of Small Scale Industry) and

\footnotetext{
${ }^{9}$ The entry level education-al qualifications for community midwives and LHVs deployed in rural areas is high school certificate, age limit and marital status for midwives is 18-35 and preferably married and for LHVs is 20 years and unmarried, widow and divorced. However, the number of midwives still remains twice the LHVs in the country. Another variant that included the annual growth rate of midwives and LHVs as separate arguments was also estimated. Growth rate of midwives raised the unpaid worker ratio and LHVs lowered the ratio and the latter was significant at the 95 percent level.

${ }^{10}$ The ambiguous impact of YREDFRR on female CFWs can be traced to the fact that its' construction in LFS contains substantial noise as it is converted from response on level of education and also contains females who may be enrolled and contributing unpaid labor to family farms.

${ }^{11}$ Another variant that included annual growth rate of middle and secondary level enrolment as arguments was also estimated. Both the indicators were statistically not significant.

${ }^{12}$ Cross section evidence in Shahnaz (2008) gives an indirect support to the above explanation. While the proportion of unpaid family workers in total employment increased from 20.8 to 27 percent during 2001-05, the percentage of youth (1524 year olds) as CFWs declined from 47 to 43 percent during the same period.

${ }^{13}$ The general government sector consists of the following two groups of resident institutional units:- a) All units of central, state or local government and b) All non-market NPIs that are controlled by government units. The classification of the functions of government (COFOG) is a classification of transactions designed to apply to general government and its subsectors. There are ten classes in the classification as follows:General public services; Defense;Public order and safety;Economic affairs;Environmental protection;Housing and community amenities;Health;Recreation, culture and religion;Education;Social protection.
} 
iii) GROPS (Annual Growth rate of Other Private Services). ${ }^{14}$ The impact of these sectoral growth rates in all the five variants of the model isrobust in terms of direction, although the extent of impact varies across the five variants of the model. In variant 1 , GRGSS and in variant 5 , GRGSSM are statistically not significant. The positive impact of growth rate in value added of small scale industry (GRSSM) and Govt. Services (GRGGS) is most likely a substitution effect stemming from greater job opportunities available over time to the primary workers, including male CFWs in rural areas. The negative impact on ratio of female share/male share unpaid work due to higher growth in value added of Other Private Services (GROPS) outweighs the impact of other two indicators and can be interpreted as the income effect due to better remuneration offered to younger family members by the private sector in rural areas. ${ }^{15}$

f) A priori a U-shaped relationship between the age of females in rural areas and participation in unpaid work is hypothesized. It stems from the observation that females in rural areas marry young, relative to their counterparts in other sectors and urban areas and thus participation of child bearing aged females in unpaid work is low and gradually rises with age. Compared with the average age 19.34 years in 2013-14 of females in rural areas at their first marriage, the observed mean age of unpaid female workers in rural areas over the 25 year period was 32.12 years with a Coefficient of Variation of 3.4 percent. Thus most of the females involved in unpaid work may be approaching their desired family size. Their participation in unpaid work may also be easier, as older siblings can take care of the younger children. Variant 5 does not precisely test the above premises, instead a U-shaped hypothesis with age of female CFWs in rural areas (AVGAGEUPFEM) and age squared terms is investigated. The impact of average age of females and its significance at 95 percent level in case of rural Pakistan indicates that over the long-run, the relationship is an inverted U-shaped one even for older females which may have passed their prime child bearing age.

\subsection{Model 2: Wage Price Specification}

The decisions relating to the participation of females in unpaid work are primarily 'internal', and depend on the dynamics and interaction of farm/family demographic profile, farm and off-farm job opportunities of primary and 'buffer' workers'. However signals emanating from inflation rates and earnings or wage rates prevailing in urban and rural areas may also impact the long-run fluctuating female CFW trends. Wage Price Model is estimated to quantify the above stated impacts. The results in Table 2 suggest the following interpretations:-

a) In periods of rising food inflation in the country reinforcing as well opposing effects may be at work, depending whether the farms are operating at a subsistence level or producing for the market. On the production side positive 'income effect' may discourage the use of unpaid work. However the 'incentive' effect to build up precautionary savings as it increases the market value of farm output may encourage higher involvement of 'buffer' female workers. Increasing food inflation also increases pressure at least in subsistence farms to switch in favor of food/minor crops including poultry output against cash crop production and thereby involve more unpaid workers. The results indicate that periods of higher food inflation (FDINFLN) raises the percentage of female CFWs and vice a versa.

b) The impact of rising general price level or growth rate of consumer price index (CPINFLN) on participation rate of females in unpaid work is ambiguous and calls for empirical validation. The results indicate that it reduces female participation in unpaid work. A tentative explanation is that negative real income effect is strong enough to compel them to seek employment outside the farm.

c) Daily wage rates of unskilled workers and their annual growth in wages in three major and cosmopolitan cities of Pakistan, namely Karachi (DLYWGKHI), Lahore (DLYWGLHR) and Peshawar (DLYWGPSHWR)

\footnotetext{
${ }^{14}$ These include renting of machinery and equipment, computer related activities (Software Export Board), education, membership organization, recreational, cultural and sporting activities, other business and other service activities and health related activities.

${ }^{15} \mathrm{~A}$ priori one would expect that the impact of annual growth rate of value added in agriculture sector would be significant although ambiguous. An extended version of equation 3 including growth rate of agriculture was estimated but it was not statistically significant although positive.
} 
are incorporated as arguments in two variants of the model to test the 'pull' factor on participation rate of females in unpaid work in rural areas. Level and growth rate of wages for unskilled workers in Karachi increase the participation of female unpaid workers in agriculture. Karachi is the largest city of Pakistan with a sizeable industrial sector and expanding construction activity. It is a magnet for unemployed and underemployed labor (specifically males) in search of work from rural areas of Pakistan. This positive impact confirms that once better wages are offered to unskilled males in Karachi, the females assume greater responsibility on farms. Peshawar is the largest city of Khyber Pakhtunkhwa, a province relatively less developed in agriculture and industrial activity. In case of Peshawar, higher absolute wages lead to a substitution of females for males on farms and therefore higher participation of females in unpaid work, but a lagged response to positive rate of increase in wages pulls females along with males to the city. Lahore is the capital city of province of Punjab, and is surrounded by rich agriculture land. A plausible reason that neither wages nor their annual growth ratesin the city affect the participation of female in unpaid work can be insignificant wage differentials of unskilled workers in the city and the per capita monetary value of the contribution of unpaid work.

d) Average earnings of male employees (ERNGMRR) and female employees (ERNGFRR) in rural areas can be meaningful determinants of decisions to participate in unpaid work. Both are included in the two variants of the model and are statistically significant. In both variants, higher earnings of male employees have a positive 'income affect' and reduce participation of females in unpaid work, while higher female employee earnings increase participation of females in unpaid work. Implicitly it is a substitution of younger females by older females (average age of unpaid female workers is around 30 years) as the former assume employee status in the non-agriculture sector in rural areas.

\subsection{Model 3:Farm Based Activity ${ }^{16}$}

In the long run change in on-farm technology and commercialization of agriculture including livestock and poultry also impact the extent and gender mix of unpaid labor supply response in individual farms. An attempt is made in this model to capture these impacts in the participation rate of female CFWs in agriculture. Two variants of the model are estimated (Table 3). In variant (1), total production of eggs (in million \#s) in the country is included and in variant (2) of the model, number of poultry (in million \#s) is included.

a) Supported by higher incomes, improved technology and commercialization, the production of milk (PRDMLK) increased annually at the average rate of 4.3 percent in the country in the last 25 years. Production of milk that was traditionally managed by females for internal use is now produced and collected in marketable quantities from individual non-dairy farms. The estimates suggest that over the years the transformation in diary industry has marginally reduced the participation of unpaid female workin agriculture. Before a conclusive finding can be reached, a more finely tuned time series data that separates the production of milk by dairy and non-dairy farms, by sex and employment status is needed. Whether the females involved in this activity on non-dairy farms are paid and/or unpaid males have assumed a greater role in its production is still a testable proposition.

b) Over the 25 year period, the production of eggs in the country (PRDEGGS) increased at an average annual rate of 5.2 percent mostly due to commercialization of this activity. The results indicate that long term yearly trends in the production of eggs, dwarfed by commercial production of eggs as in case of milk, does not explain the trend in participation of unpaid female labor in agriculture. In variant (2), number of poultry (NMBRPULTRY) is included. Over the period 1990-2015, the population of poultry birds in the country increased at an annual average rate of 8 percent, due to higher demand backed by increasing incomes and substitution effect caused by faster rise in prices of mutton and beef plus changes in dietary patterns. The statistically significant and negative impact of changing poultry numbers (dominated by commercial production) on the long-run participation rate of contributing females workers at the macro level reinforce the results of variant (1), implying a withdrawal or marginalization of this activity among the female CFWs.

c) Positive, statistically significant and impact of 1000 hectares of cropped area (CRPAREA) changing the percentage of female CFWs by 3-8 percentage points can be considered as the single most important factor in

\footnotetext{
${ }^{16}$ This macro specification is in no way a substitute or alternate to rigorous and data rich models based on multiple time use surveys. However in absence of long series of time use surveys it is an indicative specification of the how the dynamics of farm activities impact the involvement of female CFWs in the long-term.
} 
explaining the yearly variation in the participation of unpaid female labor. ${ }^{17}$ It may also point out to increasing trend of 'feminization of agriculture' within family farms over theyears asmales including unpaid males are irregularly attracted by paid opportunities outside agriculture (Intra-farm allocation model).

d) Participation of CFWs is positively related to population of livestock in the country (NMBRLVSTK), and is statistically significant in variant (2) of the model. ${ }^{18}$

e) Unpaid females at the farm level also significantly contribute in the value added of forestry products, as it also includes the value added in collection of firewood. Higher annual growth rate of value added in forestry, (GRFRSTRY) a national income indicator explains higher participation of unpaid females and vice a versa in this activity.

\section{Summary and Policy Implications}

Historical dynamics of development process in many currently developed countries document that share of Contributing Family Workers (CFWs) experienced a gradual secular decline and have now stabilized at a very low rate. ${ }^{19}$ Currently in developing countries including Pakistan, female CFWs constitute a large share of overall female employment as well as a high ratio of female to male share in agriculture. ${ }^{20}$ During 1991-2015, female CFWs as share of female labor force in agriculture of Pakistan fluctuated in the range of 52-71 percent. It was 60.15 percent in 1991 and 58.24 percent in 2015. Thus in spite of its transition to lower middle income country in the last 25 years, the phenomena of 'secular decline' in percentage of female CFWs is not observable in Pakistan. During sub-periods of the last two decades it slowed down, was stagnant or even reversed itself. In absence of long series of time use surveys in most of developing countries, the long-term trends in female CFWs and its variability in the short-run can best be explained by a mix of micro and macro indicators that include evolution of relevant socio-demographic profile, labor market indicators, wage price indicators and structural shifts/changes in sub-sectors of the economy. The objective of the present paper is to explore, model and quantify the links of macro economy to long-term trends (1991-2015) of female CFWs in agriculture using Pakistan data. As only 19 yearly observations are available against 24 selected exogenous indicators (excluding transformations), following three separate thematic specifications are estimated:- Intra-farm allocation of CFWs' labor supply (11 indicators); Wage price specification ( 7 indicators) and Farm Activity (6 indicators). The observed fluctuating trend is the net outcome of macro drivers that influence the participation of female CFWs in any given year. Across the three specifications, most of the macro drivers that increase the engagement or burden of female CFWs in agriculture and are statistically significant reflect the following structural transformation in the country:-

i) Increasing female enrolment in high schools (ENRLHIGH), rising female relative to male unemployment in rural areas (UNEMPLRURRATIO) and opportunities for male relative to female CFWs in government services (GRGGS) and small scale manufacturing (GRSSM) increased the burden and/or participation of females in on-farm unpaid jobs via the substitution effect. At policy level there is trade-off between the intergenerational benefits of more educated female population and costs incurred by the current generationfemale CFWs in agriculture.

ii) Rising levels or positive growth in wages of unskilled labor in metropolitan cities (DLYWGKHI, DLYWGPSHWR and GRWGKHI) attract male CFWs and through 'substitution effect' lead to feminization of agriculture.

iii) The direction of changes in crop and non-crop production processes and the participation of female CFWs in agriculture are also positively related. The increase in CRPAREA leading to higher participation of female CFWs suggest 'feminization of agriculture' implicitly in times of favorable climatic conditions including water supply and vice a versa. Drivers such as NMBRLVSTK and GRFRSTRY suggest the continuation of positive traditional relationship with unpaid female family members.

\footnotetext{
${ }^{17}$ Among all the independent variables, CRPAREA's Pearson correlation with UNPDFAG is the highest and significant at 99 percent level. Extent of cropped area's correlation with water availability and other climatic conditions indirectly and implicitly also determine 'feminization of agriculture' link to climatic changes.

${ }^{18}$ It is defined as aggregate number of Buffalo, Cattle, Goat and Sheep in the country.

${ }^{19}$ In case of US, Daly (1982) found that unpaid family workers as a percent of employment dropped from 2.7 in 1950 to 0.7 percent in 1981. Unpaid females constituting 6.1 percent of total female employment in 1950 dropped to 1.2 percent in 1981.

${ }^{20}$ In Latin American countries (LAC region) the ratio of female share/male share in CFWs during 1999-2008 was 2.02. In South Asia the corresponding ratio was 4.77. http://www.oecd.org/dev/pgd/48619715.pdf 
Across the three specifications, the indicators that decrease the engagement or burden of female CFWs in agriculture and are statistically significant reflect the following structural transformation or stability in the country:-

a) Demographic transition and higher education backed by skill acquisition (JOBRATIO) by females lead to absorption of females into growing non-farm rural job opportunities in the health sector. This caused a decline and vice a versa in the participation of female CFWs in the agriculture sector.

b) Increasing/decreasing yearly activities of the private sector (GROPS) in rural areas (education, health, IT services) enhance/diminish opportunities of younger female CFWs. This yields positive 'income effect' of reducing/increasing the yearly participation of older female CFWs in agriculture underjoint utility function.

c) Similarly yearly increase in the male labor force participation (LFPR) and average earnings of male employees in rural areas (ERNGMRR) via the 'income effect' reduces and vice a versa, the participation of females CFWs in agriculture.

d) Over the long-term, the commercialization, adoption of changing technology of production and growth/strengthening of value chains in the production of milk (PRDMLK) and poultry (NMBRPULTRY) has reduced the involvement of female CFWs in agriculture.

e) Increasing average life span of females in rural areas will continue to have miniscule impact on reducing the participation of female CFWs in agriculture.

From a 'quality of jobs' perspective, unpaid work (SNA type) whether done by family or non-family members runs counter to the universally recognized and accepted concept of decent work and is a major component of 'vulnerable' employment defined by ILO. However, in developing countries female unpaid work is a major contributor to the growth of self-employed and informal sector, namely agriculture. At subsistence level farming and decision-making under a joint utility function, the contribution of unpaid work to increasing economic welfare of farm households and production at the macro level is well recognized and quantified in many countries. Given the informal nature of the agriculture sector and complex interaction of socio-economic-demographic drivers determining the participation of female CFWs at the individual farm, its amenability to various tax and expenditure, wage, social protection and social policies in developing countries however remains weak, limited and questionable. Within this matrix of policies, the results for Pakistan provide additional policy evidence that expansion in selected sub-formal sectors, namely health services, other private services and commercialization of dairy industry increased decent jobs and reduced participation of female CFWs. Increasing jobs opportunities for males in rural areas or urban centers is a source of higher incomes and can discourage female unpaid work, although higher growth rate in small scale industries and government services encouraged 'feminization of agriculture' in the opposite direction. Similarly increasing enrolment in high schools may have come at the cost of increased burden on older female family members. Thus the evidence over a 25 year time span in contributing to secular decline of female CFWs in agriculture is at best mixed. The net impact in the short to medium term is the outcome of relative strength of above forces fuelling negative or positive growth in participation of female CFWs in agriculture. Overall the substitution effects outweigh the income effects and from a policy perspective suggest that only a structural transformation in the agriculture sector and rural labor markets induced by policies that consolidate small agriculture farms into commercially viable farms in parallel with growth of public and private service sector (conducive to absorption of females) in rural areas, or create incentives to adopt cost-efficient small farm technology to generate higher incomes and thereby achieve a balance between paid and unpaid work. Alternatively, government can wait and rely on slow moving population-demographic trends, educational attainment and rural/urban migration to witness a secular and permanent decline in the engagement of female CFWs in agriculture. 
Fig.1. Trend of Main Female Labor Market Indicators in Rural Pakistan

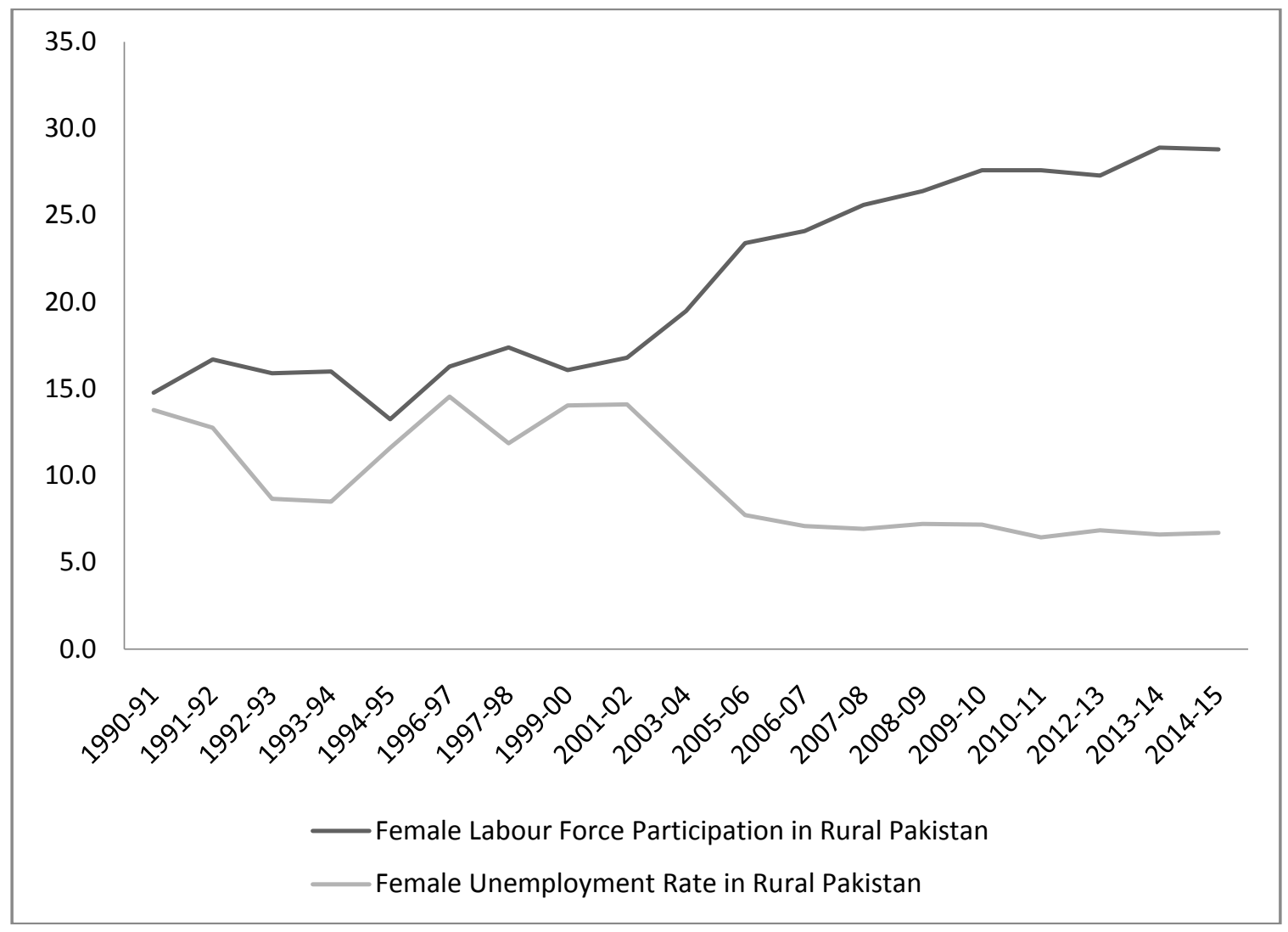

Fig.2. Percentageof Female CFWs and Male CFWs in Agriculture

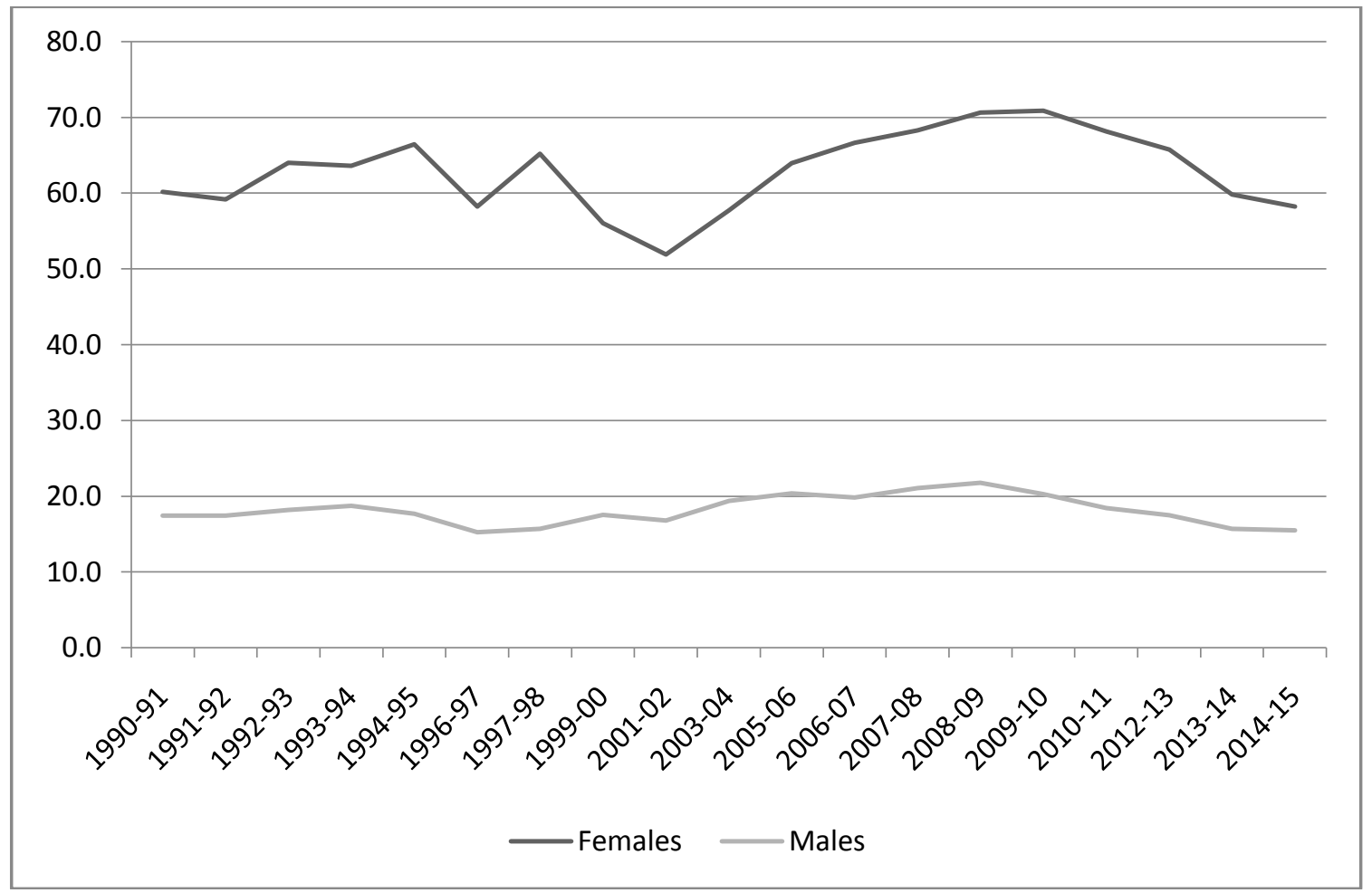


Fig.3. Ratio of Percentage of Female to Male CFWs in Agriculture

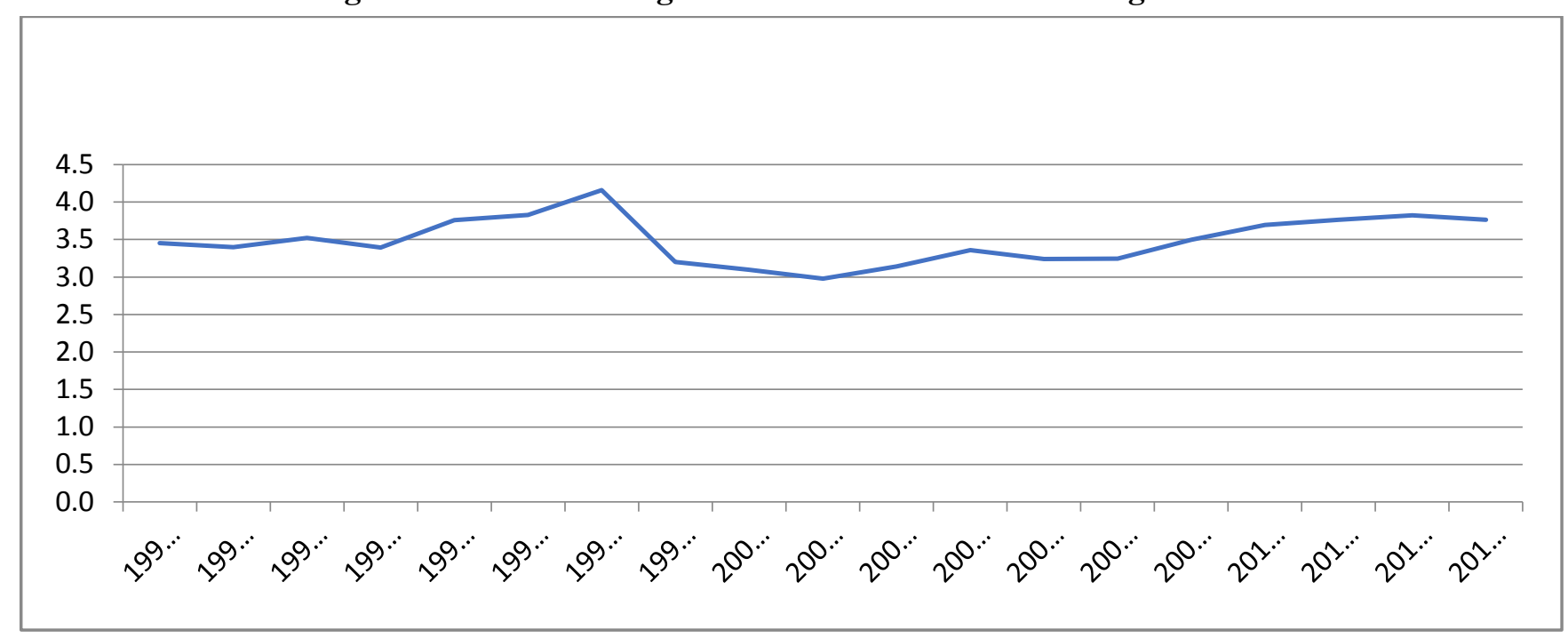




\section{Table 1: Intra-farm Allocation of CFWs' Labor Supply}

Dependent Variable: Ratio of Female CFWs share to Male CFWs share in Agriculture (UNPDRATIO)

\begin{tabular}{|c|c|c|c|c|c|c|c|c|c|c|}
\hline \multirow[b]{2}{*}{ Variable } & \multicolumn{2}{|c|}{ (1) } & \multicolumn{2}{|c|}{ (2) } & \multicolumn{2}{|c|}{ (3) } & \multicolumn{2}{|c|}{ (4) } & \multicolumn{2}{|c|}{ (5) } \\
\hline & Coefficient & Prob. & Coefficient & Prob. & Coefficient & Prob. & Coefficient & Prob. & Coefficient & Prob. \\
\hline $\mathrm{C}$ & -0.895 & 0.6855 & $-0.955 * *$ & 0.0108 & 17.523 & 0.8950 & $-1.933 * *$ & 0.0189 & $-46.308 * *$ & 0.0169 \\
\hline LFPRATIO & & & $-0.354 * * *$ & 0.0059 & & & & & & \\
\hline LFPRATIO(-1) & $-0.181 *$ & 0.0719 & & & 0.011 & 0.9412 & 0.362 & 0.1245 & 0.095 & 0.6728 \\
\hline UNEMPLRATIO & $-0.596 * *$ & 0.0240 & -0.282 & 0.1160 & & & & & & \\
\hline UNEMPLRURRATIO(-1) & & & & & $0.234 * *$ & 0.0397 & $0.264 * * *$ & 0.0045 & $0.298 * * *$ & 0.0027 \\
\hline JOBRATIO & & & $1.330 * * *$ & 0.0000 & $0.730 * *$ & 0.0383 & $0.532 * * *$ & 0.0055 & $0.716^{* *}$ & 0.0107 \\
\hline JOBRATIO(-1) & $0.783 * *$ & 0.0229 & & & & & & & & \\
\hline YREDFRR & $0.930 *$ & 0.0519 & & & 0.244 & 0.6800 & & & & \\
\hline ENRLMDL & & & $-0.002 * * *$ & 0.0007 & & & & & & \\
\hline ENRLMDL(-1) & & & & & & & -0.000 & 0.2383 & -0.000 & 0.4868 \\
\hline ENRLHIGH & & & $0.006 * * *$ & 0.0000 & & & $0.003 * * *$ & 0.0016 & $0.003 * * *$ & 0.0071 \\
\hline GRGGS & 0.006 & 0.2034 & $0.064 * * *$ & 0.0001 & $0.020 * *$ & 0.0147 & $0.053 * * *$ & 0.0016 & $0.049 * * *$ & 0.0047 \\
\hline GRSSM & $0.099 * * *$ & 0.0006 & $0.048 * * *$ & 0.0176 & $0.056^{* *} *$ & 0.0240 & $0.058 * *$ & 0.0365 & 0.030 & 0.1484 \\
\hline GROPS & $-0.151 * * *$ & 0.0002 & $-0.113 * * *$ & 0.0000 & $-0.126 * * *$ & 0.0013 & $-0.165^{* * *}$ & 0.0001 & $-0.116^{* *}$ & 0.0203 \\
\hline AVGAGEUPFEM & & & & & & & & & $2.691 * *$ & 0.0210 \\
\hline AVGAGEUPFEM $^{\wedge} 2$ & & & & & & & & & $-0.041 * *$ & 0.0228 \\
\hline $\mathrm{AR}(1)$ & $1.699 * * *$ & 0.0010 & $-1.874 * * *$ & 0.0017 & $0.993 * * *$ & 0.0000 & $-0.958 * *$ & 0.0226 & $-1.907 * * *$ & 0.0059 \\
\hline $\mathrm{AR}(2)$ & $-1.153 * *$ & 0.0116 & $-0.925^{*}$ & 0.0833 & & & & & $-1.135^{* *}$ & 0.0392 \\
\hline Adj. R-Squared & 0.846 & & 0.870 & & 0.818 & & 0.847 & & 0.970 & \\
\hline Std.Error of Estimate & 0.133 & & 0.118 & & 0.139 & & 0.128 & & 0.059 & \\
\hline F-statistic & 10.137 & & 11.754 & & 10.018 & & 10.814 & & 41.217 & \\
\hline Prob. (F-statistic) & 0.005 & & 0.003 & & 0.002 & & 0.002 & & 0.005 & \\
\hline D-W & 1.878 & & 2.245 & & 1.912 & & 2.256 & & 2.083 & \\
\hline
\end{tabular}

\footnotetext{
Sig. level (*) $90 \%,(* *) 95 \%,(* * *) 99 \%$
} 
Table 2: Wage Price Specification

Dependent Variable: Percentage of Unpaid Female Workers in Agriculture (UNPDFAG)

\begin{tabular}{l|ll|ll|} 
& \multicolumn{2}{c|}{$(1)$} & \multicolumn{2}{c|}{ (2) } \\
Variable & Coefficient & Prob. & Coefficient & Prob. \\
\hline C & & & & \\
CPINFLN & $60.073^{* * *}$ & 0.0000 & $55.178^{* * *}$ & 0.0000 \\
FDINFLN & $-1.487 * * *$ & 0.0001 & $-0.973^{* *}$ & 0.0359 \\
DLYWGKHI & $1.438^{* * *}$ & 0.0004 & $1.155^{* * *}$ & 0.0078 \\
DLYWGLHR & $0.090^{*}$ & 0.0641 & - & \\
DLYWGPSHWR & -0.030 & 0.2717 & - & \\
GRWGKHI(-1) & $0.096^{* *}$ & 0.0292 & - & \\
GRWGLHR & & & $13.402 * *$ & 0.0340 \\
GRWGPSHWR(-1) & & & 1.688 & 0.8060 \\
ERNGMRR & & $-3.380^{*}$ & 0.098 \\
ERNGFRR & $-0.011^{* * *}$ & 0.0033 & $-0.004 * *$ & 0.0152 \\
MA(1) & $0.010^{* * *}$ & 0.0016 & $0.007 * * *$ & 0.0056 \\
\hline & $0.999^{* * *}$ & 0.0035 & $0.999 * *$ & 0.0224 \\
Adj. R-Squared & & & & \\
Std.Error of Estimate & 0.741 & & 0.781 & \\
F-statistic & 2.655 & & 2.529 & \\
Prob. (F-statistic) & 7.439 & & 8.118 & \\
D-W & 0.002 & & 0.004 & \\
\hline
\end{tabular}

Sig. level (*) 90\%, (**) 95\%, (***) 99\%

Table 3: Farm Activity

Dependent Variable: Percentage of Unpaid Female Workers in Agriculture (UNPDFAG)

\begin{tabular}{|c|c|c|c|c|}
\hline \multirow[b]{2}{*}{ Variables } & \multicolumn{2}{|l|}{ (1) } & \multicolumn{2}{|c|}{ (2) } \\
\hline & Coefficients & Prob. & Coefficients & Prob. \\
\hline $\mathrm{C}$ & $-147.217 * * *$ & 0.0008 & $-88.875^{* *}$ & 0.0135 \\
\hline PRDMLK & $-0.002 * * *$ & 0.0002 & $-0.002 * * *$ & 0.0044 \\
\hline PRDEGGS & 0.002 & 0.4833 & & \\
\hline NMBRPULTRY & & & $-0.046 * *$ & 0.012 \\
\hline CRPAREA & $8.409 * * *$ & 0.0003 & $3.289 * *$ & 0.0415 \\
\hline NMBRLVSTK & 0.535 & 0.2329 & $1.235 * * *$ & 0.0005 \\
\hline GRFRSTY & $0.100 * *$ & 0.0249 & $0.047 *$ & 0.0815 \\
\hline $\mathrm{AR}(1)$ & 0.276 & 0.3031 & $1.052 * * *$ & 0.0007 \\
\hline $\mathrm{AR}(2)$ & $-0.828 * *$ & 0.0260 & $-0.731 * * *$ & 0.0089 \\
\hline Adj. R-square & 0.773 & & 0.811 & \\
\hline Std.Error of Est. & 2.570 & & 2.346 & \\
\hline F-statistic & 8.806 & & 10.828 & \\
\hline Prob. (F-statistic) & 0.002 & & 0.001 & \\
\hline D-W & 1.895 & & 1.993 & \\
\hline
\end{tabular}

Sig. level (*) 90\%, (**) 95\%, (***) 99\%

Acknowledgement: The author is indebted to Ms. Lubna Shahnaz for diligently extracting and compiling the data series of various indicators from primary LFS data files and macro data of last 19 years. 


\section{References}

Abraham,V.,(2009).Employment Growth in India: Distress Driven? Economic and Political Weekly, Vol. 44, No.16, April, Pp. 97-104.

Arshad, Z, et al., (2008). The Economic Contribution of Pakistani Women through there Unpaid Labour. Society for Alternative Media and Research and Health Bridge, Islamabad, Pakistan, August.

Bell, D.E.,\& Kenney, R.L., (2009). Altruistic Utility Function for Joint Decisions,In S. J. Brams et al., (Eds.),The Mathematics of Preference, Choice and Order, Essays in Honor of Peter C. Fishburn. Springer-Verlag, Berlin, Heidelberg.

Ejaz, M., (2011).Determinants ofFemale Labour Force Participation in Pakistan: An Instrumental Variable Approach. Centre for Research in Economics and Business (CREB), Working Paper No.01-11, Lahore School of Economics.

Fontana, M., (2013).Gender in Economy-wide Modelling, In S. Rai, G. Waylen (Eds.), New Frontiers in Feminist Political Economy (pp.157-177).Routledge.

Isran, S., \&Isran, M.A., (2012).Low Female Labour Participation in Pakistan: Causes andConsequences,Pakistan Journal of Social Sciences, Vol. 32, No. 2, pp. 453-468.

Hirway, I., (2015).Unpaid Work and the Economy: Linkages and Their Implications.Working Paper No.838.Levy Economics Institute of Bard College.

Rahman, I.R.,\&Rizwanul, I., (2013). Female Labour Force Participation in Bangladesh: Trends, Drivers and Barriers. Decent Work Technical Support Team (DWT) for South Asia, India. October.

Sarwar, F., \&Abbasi, A.S., (2013). An In-Depth Analysis of Women Labour Force Participation in Pakistan, Middle-East Journal of Scientific Research, Vol. 15(2), Pp. 208-215.

Shahnaz, L., Khalid, U.,\& Akhtar, S., (2008).Unpaid Family Workers: Unravelling the mystery of falling unemployment. DiscussionPaper No.17.Centre for Research on Poverty Reduction and Income Distribution,January. 


\begin{tabular}{|c|c|c|c|c|c|}
\hline \multicolumn{6}{|c|}{ ANNEX A } \\
\hline \multicolumn{6}{|c|}{ Profile of Indicators used in the study } \\
\hline \multirow[t]{2}{*}{ Variables } & Mean & Coeff. of & Unit of Measure & Data Source & Definitions \\
\hline & & Variation $(\%)$ & & & \\
\hline UNPDRATIO & 3.49 & 8.86 & Ratio & LFS & $\begin{array}{c}\text { Percentage of Female CFWs to Male CFWs in Agriculture. CFWs are a } \\
\text { percentage of respective total labour force in rural areas. }\end{array}$ \\
\hline UNPDFAG & 62.87 & 8.30 & Percentage & LFS & Percentage of Female CFWs in Agriculture. \\
\hline LFPRATIO & 3.62 & 27.44 & Ratio & LFS & Labour force Participation rate of males to females in rural areas \\
\hline UNEMPLRATIO & 1.48 & 10.53 & Ratio & LFS & Open unemployment rates in urban to rural areas \\
\hline UNEMPLRURRATIO & 2.34 & 33.48 & Ratio & LFS & Open unemployment rates of female to male in rural areas \\
\hline JOBRATIO & 3.60 & 29.99 & Ratio & Health Section, PES & Total number of midwives to lady health visitors \\
\hline YREDFRR & 3.19 & 18.96 & years & LFS & Average years of education of females in rural areas \\
\hline ENRLMDL & 1841.84 & 35.76 & in $000^{\prime} s$ & $\begin{array}{l}\text { Education Section, } \\
\text { PES }\end{array}$ & No. females enrolled in middle schools of the country \\
\hline ENRLHIGH & 798.21 & 45.26 & in $000^{\prime} s$ & $\begin{array}{l}\text { Education Section, } \\
\text { PES }\end{array}$ & No. females enrolled in high schools of the country \\
\hline GRGGS & 6.39 & 86.90 & Growth Rate & $\begin{array}{l}\text { National Accounts, } \\
\text { PES }\end{array}$ & Annual Growth rate of General Govt. Services \\
\hline GRSSM & 10.09 & 28.86 & Growth Rate & $\begin{array}{c}\text { National Accounts, } \\
\text { PES }\end{array}$ & Annual Growth rate of Small Scale Manufacturing \\
\hline GROPS & 8.32 & 37.01 & Growth Rate & $\begin{array}{c}\text { National Accounts, } \\
\text { PES }\end{array}$ & Annual Growth rate of Other Private Services \\
\hline AVGAGEUPFEM & 32.12 & 3.37 & years & LFS & Average age of Females CFWs in rural areas \\
\hline CPINFLNI & 12.04 & 41.17 & Growth Rate & Inflation, PES & Annual change in Consumer Price Index \\
\hline FDINFLN & 13.06 & 42.90 & Growth Rate & Inflation, PES & Annual Change in Food Price Index \\
\hline DLYWGKHI & 241.69 & 65.62 & Nominal PKRs. & Employment, PES & Daily wages of unskilled workers in Karachi \\
\hline DLYWGLHR & 223.38 & 71.51 & Nominal PKRs. & Employment, PES & Daily wages of unskilled workers in Lahore \\
\hline DLYWGPSHWR & 175.42 & 83.39 & Nominal PKRs. & Employment, PES & Daily wages of unskilled workers in Peshawar \\
\hline GRWGKHI & 0.14 & 110.02 & Growth Rate & $\begin{array}{l}\text { Derived from } \\
\text { DLYWGKHI }\end{array}$ & Annual growth rate of daily wages of unskilled workers in Karachi \\
\hline GRWGLHR & 0.15 & 86.89 & Growth Rate & $\begin{array}{l}\text { Derived from } \\
\text { DLYWGLHR }\end{array}$ & Annual growth rate of daily wages of unskilled workers in Lahore \\
\hline GRWGPSHWR & 0.16 & 95.46 & Growth Rate & $\begin{array}{l}\text { Derived from } \\
\text { DLYWGPSWHR }\end{array}$ & Annual Growth rate of daily wages of unskilled workers in Peshawar \\
\hline ERNGMRR & 5398.21 & 73.10 & Nominal PKRs. & LFS & Monthly earnings of male employees in rural areas \\
\hline ERNGFRR & 3014.83 & 72.43 & Nominal PKRs. & LFS & Monthly earnings of female employees in rural areas \\
\hline PRDMLK & 28498.89 & 31.93 & 000'Tonnes & Agriculture, PES & Total production of milk in the country \\
\hline PRDEGGS & 9019.90 & 39.11 & Million Numbers & Agriculture, PES & Total production of eggs in the country \\
\hline NMBRPULTRY & 448.05 & 52.38 & Million Numbers & Agriculture, PES & Total number of poultry in the country \\
\hline CRPAREA & 22.79 & 3.07 & 000' Hectares & Agriculture, PES & Total cropped area in the country \\
\hline NMBRLVSTK & 131.52 & 19.00 & Million Numbers & Agriculture, PES & Total number of livestock in the country \\
\hline GRFRSTY & -0.13 & -13087.58 & Growth Rate & $\begin{array}{c}\text { National Accounts, } \\
\text { PES }\end{array}$ & Annual growth rate of forestry in the country \\
\hline
\end{tabular}

PES: Various Issues of Pakistan Economic Survey, LFS: Various Issues of Labour Force Surveys 


\section{ANNEX B}

MODEL 1: CORRELATION MATRIX

\begin{tabular}{|c|c|c|c|c|c|c|c|c|c|c|c|}
\hline UNPDRATIO & $\begin{array}{l}\text { UNPDRATIO } \\
1\end{array}$ & LFPRATIO & UNEMPLRATIO & UNEMPLRURRATIO & JOBRATIO & YREDFRR & ENRLMDL & ENRLHIGH & GRGGS & GRSSM & GROPS \\
\hline \multirow{2}{*}{ LFPRATIO } & -0.0335 & 1 & & & & & & & & & \\
\hline & 0.89 & & & & & & & & & & \\
\hline \multirow[t]{2}{*}{ UNEMPLRATIO } & 0.2661 & -0.3682 & 1 & & & & & & & & \\
\hline & 0.27 & 0.12 & & & & & & & & & \\
\hline \multirow[t]{2}{*}{ UNEMPLRURRATIO } & 0.2698 & 0.8566 & -0.4163 & 1 & & & & & & & \\
\hline & 0.26 & 0.00 & 0.08 & & & & & & & & \\
\hline \multirow{2}{*}{ JOBRATIO } & 0.0356 & 0.9616 & -0.4480 & 0.9083 & 1 & & & & & & \\
\hline & 0.89 & 0.00 & 0.05 & 0.00 & & & & & & & \\
\hline \multirow{2}{*}{ YREDFRR } & -0.2985 & -0.4525 & -0.0137 & -0.4422 & -0.4698 & 1 & & & & & \\
\hline & 0.21 & 0.05 & 0.96 & 0.06 & 0.04 & & & & & & \\
\hline \multirow{2}{*}{ ENRLMDL } & 0.1239 & -0.9251 & 0.5029 & -0.8490 & -0.9501 & 0.4015 & 1 & & & & \\
\hline & 0.61 & 0.00 & 0.03 & 0.00 & 0.00 & 0.09 & & & & & \\
\hline \multirow[t]{2}{*}{ ENRLHIGH } & 0.1435 & -0.9234 & 0.5050 & -0.8378 & -0.9524 & 0.3413 & 0.9915 & 1 & & & \\
\hline & 0.56 & 0.00 & 0.03 & 0.00 & 0.00 & 0.15 & 0.00 & & & & \\
\hline \multirow[t]{2}{*}{ GRGGS } & -0.0405 & -0.3654 & 0.4738 & -0.4155 & -0.4424 & 0.5729 & 0.3991 & 0.3662 & 1 & & \\
\hline & 0.87 & 0.12 & 0.04 & 0.08 & 0.06 & 0.01 & 0.09 & 0.12 & & & \\
\hline \multirow[t]{2}{*}{ GRSSM } & -0.0701 & -0.0046 & 0.2657 & 0.0240 & 0.0298 & 0.3062 & 0.0736 & 0.0232 & 0.4871 & 1 & \\
\hline & 0.78 & 0.99 & 0.27 & 0.92 & 0.90 & 0.20 & 0.76 & 0.93 & 0.03 & & \\
\hline \multirow[t]{2}{*}{ GROPS } & -0.3597 & 0.1878 & 0.1013 & 0.0485 & 0.1601 & 0.1985 & -0.0793 & -0.1268 & 0.4520 & 0.8428 & 1 \\
\hline & 0.13 & 0.44 & 0.68 & 0.84 & 0.51 & 0.42 & 0.75 & 0.60 & 0.05 & 0.00 & \\
\hline \multirow[t]{2}{*}{ AVGAGEUPFEM } & -0.1252 & 0.3428 & 0.2224 & 0.2135 & 0.2525 & -0.1198 & -0.2035 & -0.2026 & 0.1592 & 0.1488 & 0.4315 \\
\hline & 0.61 & 0.15 & 0.36 & 0.38 & 0.30 & 0.63 & 0.40 & 0.41 & 0.52 & 0.54 & 0.07 \\
\hline
\end{tabular}

Probability level below the Correlation Coefficients 


\begin{tabular}{|c|c|c|c|c|c|c|c|c|c|c|c|c|c|c|c|c|}
\hline & & & & & & & \multicolumn{3}{|c|}{ ANNEXC } & & & & & & & \\
\hline & & & & & & & \multicolumn{3}{|c|}{ MODEL 2 and 3: CORRELATION MATRIX } & & & & & & & \\
\hline & UNPDFAG & CPINFLNI & FDINFLN & DLYWGKHI & DLYWGLHR & DLYWGPSHWR & GRWGKHI & GRWGLHR & GRWGPSHWR & ERNGMRR & ERNGFRR & PRDMLK & PRDEGGS & NMBRPULTRY & CRPAREA & NMBRLVSTK \\
\hline UNPDFAG & 1 & & & & & & & & & & & & & & & \\
\hline \multirow[t]{2}{*}{ CPINFLNI } & 0.3290 & 1 & & & & & & & & & & & & & & \\
\hline & 0.17 & & & & & & & & & & & & & & & \\
\hline \multirow[t]{2}{*}{ FDINFLN } & 0.5574 & 0.9304 & 1 & & & & & & & & & & & & & \\
\hline & 0.01 & 0.00 & & & & & & & & & & & & & & \\
\hline \multirow[t]{2}{*}{ DLYWGKHI } & 0.2510 & -0.0113 & 0.0178 & 1 & & & & & & & & & & & & \\
\hline & 0.30 & 0.96 & 0.94 & & & & & & & & & & & & & \\
\hline \multirow[t]{2}{*}{ DLYWGLHR } & 0.1819 & -0.0673 & -0.0467 & 0.9798 & 1 & & & & & & & & & & & \\
\hline & 0.46 & 0.78 & 0.85 & 0.00 & & & & & & & & & & & & \\
\hline \multirow[t]{2}{*}{ DLYWGPSHWR } & 0.2058 & -0.0606 & -0.0369 & 0.9762 & 0.9895 & 1 & & & & & & & & & & \\
\hline & 0.40 & 0.81 & 0.88 & 0.00 & 0.00 & & & & & & & & & & & \\
\hline \multirow[t]{2}{*}{ GRWGKHI } & 0.0227 & 0.7268 & 0.5477 & -0.1072 & -0.1376 & -0.1541 & 1 & & & & & & & & & \\
\hline & 0.93 & 0.00 & 0.02 & 0.67 & 0.59 & 0.54 & & & & & & & & & & \\
\hline \multirow[t]{2}{*}{ GRWGLHR } & 0.0035 & 0.4353 & 0.3334 & 0.1469 & 0.2041 & 0.1315 & 0.4597 & 1 & & & & & & & & \\
\hline & 0.99 & 0.07 & 0.18 & 0.56 & 0.42 & 0.60 & 0.05 & & & & & & & & & \\
\hline \multirow[t]{2}{*}{ GRWGPSHWR } & 0.1794 & 0.4734 & 0.4700 & 0.1046 & 0.0612 & 0.0833 & 0.3185 & 0.4575 & 1 & & & & & & & \\
\hline & 0.48 & 0.05 & 0.05 & 0.68 & 0.81 & 0.74 & 0.20 & 0.06 & & & & & & & & \\
\hline \multirow[t]{2}{*}{ ERNGMRR } & 0.2760 & -0.0370 & 0.0079 & 0.9898 & 0.9872 & 0.9879 & -0.1508 & 0.1275 & 0.0634 & 1 & & & & & & \\
\hline & 0.25 & 0.88 & 0.97 & 0.00 & 0.00 & 0.00 & 0.55 & 0.61 & 0.80 & & & & & & & \\
\hline \multirow[t]{2}{*}{ ERNGFRR } & 0.3532 & -0.0010 & 0.0503 & 0.9696 & 0.9607 & 0.9573 & -0.1319 & 0.1201 & 0.0558 & 0.9866 & 1 & & & & & \\
\hline & 0.14 & 1.00 & 0.84 & 0.00 & 0.00 & 0.00 & 0.60 & 0.63 & 0.83 & 0.00 & & & & & & \\
\hline \multirow[t]{2}{*}{ PRDMLK } & 0.2615 & -0.0243 & 0.0438 & 0.9704 & 0.9281 & 0.9136 & -0.1513 & 0.1415 & 0.1575 & 0.9481 & 0.9318 & 1 & & & & \\
\hline & 0.28 & 0.92 & 0.86 & 0.00 & 0.00 & 0.00 & 0.55 & 0.58 & 0.53 & 0.00 & 0.00 & & & & & \\
\hline \multirow[t]{2}{*}{ PRDEGGS } & 0.2693 & -0.0256 & 0.0391 & 0.9863 & 0.9703 & 0.9638 & -0.1708 & 0.1601 & 0.1343 & 0.9831 & 0.9633 & 0.9843 & 1 & & & \\
\hline & 0.26 & 0.92 & 0.87 & 0.00 & 0.00 & 0.00 & 0.50 & 0.53 & 0.60 & 0.00 & 0.00 & 0.00 & & & & \\
\hline \multirow[t]{2}{*}{ NMBRPULTRY } & 0.2312 & 0.0189 & 0.0473 & 0.9790 & 0.9797 & 0.9790 & -0.0552 & 0.1525 & 0.0918 & 0.9833 & 0.9622 & 0.9420 & 0.9754 & 1 & & \\
\hline & 0.34 & 0.94 & 0.85 & 0.00 & 0.00 & 0.00 & 0.83 & 0.55 & 0.72 & 0.00 & 0.00 & 0.00 & 0.00 & & & \\
\hline \multirow[t]{2}{*}{ CRPAREA } & 0.5951 & 0.2022 & 0.3410 & 0.5138 & 0.3768 & 0.3639 & 0.1188 & -0.0291 & 0.1274 & 0.4735 & 0.5412 & 0.6115 & 0.5153 & 0.4442 & 1 & \\
\hline & 0.01 & 0.41 & 0.15 & 0.02 & 0.11 & 0.13 & 0.64 & 0.91 & 0.61 & 0.04 & 0.02 & 0.01 & 0.02 & 0.06 & & \\
\hline \multirow[t]{2}{*}{ NMBRLVSTK } & 0.2980 & -0.0328 & 0.0432 & 0.9841 & 0.9618 & 0.9565 & -0.1813 & 0.1296 & 0.1416 & 0.9797 & 0.9628 & 0.9872 & 0.9977 & 0.9696 & 0.5439 & 1 \\
\hline & 0.22 & 0.89 & 0.86 & 0.00 & 0.00 & 0.00 & 0.47 & 0.61 & 0.58 & 0.00 & 0.00 & 0.00 & 0.00 & 0.00 & 0.02 & \\
\hline \multirow[t]{3}{*}{ GRFRSTY } & 0.3824 & 0.1621 & 0.3054 & 0.0332 & 0.0298 & 0.0727 & -0.0911 & -0.1880 & 0.3700 & 0.0750 & 0.0875 & 0.0590 & 0.0893 & 0.0901 & -0.0365 & 0.1245 \\
\hline & 0.11 & 0.51 & 0.20 & 0.89 & 0.90 & 0.77 & 0.72 & 0.46 & 0.13 & 0.76 & 0.72 & 0.81 & 0.72 & 0.71 & 0.88 & 0.61 \\
\hline & \multicolumn{5}{|c|}{ Probabilty Level below the Correlation Coefficients } & & & & & & & & & & & \\
\hline
\end{tabular}

